\title{
Modeling of Cross-Coupling Magnetic Saturation in Signal-Injection-Based Sensorless Control of Permanent-Magnet Brushless AC Motors
}

\author{
Y. Li, Z. Q. Zhu, D. Howe, and C. M. Bingham
}

Department of Electronic and Electrical Engineering, University of Sheffield, Sheffield S1 3JD, U.K.

\begin{abstract}
An improved brushless AC motor model is proposed for use in signal-injection-based sensorless control schemes by accounting for cross-coupling magnetic saturation between the $d$-and $q$-axes. The incremental self- and mutual-inductance characteristics are obtained by both finite-element analysis and measurements, and have been successfully used to significantly reduce the error in the rotor position estimation of sensorless control.
\end{abstract}

Index Terms-Brushless AC motor, cross-coupling effect, sensorless, signal injection.

\section{INTRODUCTION}

$\mathbf{S}$ ENSORLESS control of permanent-magnet (PM) brushless AC (BLAC) motors is desirable in order to reduce the system complexity and cost, and to improve reliability. Unlike other sensorless control methods whose performance is problematic during starting and low-speed operation, signal-injection-based sensorless schemes exhibit excellent control performance at standstill and low speeds. However, it was found experimentally in [1] that the error in the estimated rotor position increases with the load current, while in [2] it was shown that a significant error can arise due to the influence of cross-coupling magnetic saturation between the $d$ - and $q$-axes. Although the effect of magnetic saturation on the cross coupling in permanent-magnet brushless machines is well known [3], it is generally neglected in the implementation of signal-injection-based sensorless control [1], [4].

This paper, therefore, presents a simple way to account for the cross-coupling effect. Incremental self- and mutual-inductance characteristics for use in an improved BLAC motor model are obtained by both finite-element analysis and measurements. They are subsequently used in a signal-injection-based sensorless control scheme and a significant reduction in the error in the estimated rotor position is achieved.

\section{Modeling of Cross-Coupling EFFeCt in BLAC Motor}

When cross coupling between the $d$ - and $q$-axes is considered, the voltage equations of a BLAC motor in the rotor reference $d q$-axis frame are [3]

$$
\left[\begin{array}{l}
v_{d} \\
v_{q}
\end{array}\right]=\left[\begin{array}{cc}
R_{s}+L_{d h} p & -\omega_{r} L_{q}+L_{d q h} p \\
\omega_{r} L_{d}+L_{q d h} p & R_{s}+L_{\mathrm{qh}} p
\end{array}\right]\left[\begin{array}{c}
i_{d} \\
i_{q}
\end{array}\right]+\left[\begin{array}{c}
0 \\
\omega_{r} \psi_{m}
\end{array}\right]
$$

where $v_{d}, v_{q}, i_{d}, i_{q}, L_{d}$, and $L_{q}$ are the $d$ - and $q$-axis voltages, currents, and apparent self-inductances, respectively, and $L_{d h}, L_{q h}, L_{d q h}$, and $L_{q d h}$ are the incremental $d$ - and $q$-axis self and mutual inductances, respectively. $R_{s}$ is the phase resistance, $\psi_{m}$ is the flux-linkage due to the permanent magnets, $\omega_{r}$ is the angular rotational speed, and $p=d / d t$.

Digital Object Identifier 10.1109/TMAG.2007.892319
High-frequency signal injection components in (1) can be approximated by

$$
\left[\begin{array}{c}
v_{d h} \\
v_{q h}
\end{array}\right] \approx\left[\begin{array}{cc}
L_{d h} & L_{d q h} \\
L_{q d h} & L_{q h}
\end{array}\right] \cdot p\left[\begin{array}{c}
i_{d h} \\
i_{q h}
\end{array}\right]
$$

where $v_{d h}, v_{q h}, i_{d h}$ and $i_{q h}$ are the high-frequency components of the $d$ - and $q$-axis voltages and currents, respectively.

If the high-frequency signal, $v_{\mathrm{sig}}=V_{\mathrm{sig}} \sin \left(2 \pi f_{\mathrm{HF}} t\right)$, is injected in the $d$-axis, the error in the estimated rotor position, $\Delta \theta$, can be calculated as

$$
\Delta \theta \approx k_{\Delta \theta} \cdot\left[i_{q h}^{e}+\left(L_{d q h} / L_{q h}\right) i_{d h}^{e}\right]
$$

where $i_{d h}^{e}, i_{q h}^{e}$ are the high-frequency components of the estimated $d$ - and $q$-axis currents, $k_{\Delta \theta}=\left(p\left(L_{\text {avg }}^{2}-L_{\text {dif_c } c}^{2}\right) /-2 v_{\text {sig }}\left(L_{\text {dif }}+L_{d q h}^{2} / L_{q h}\right)\right)$, $L_{\mathrm{avg}}=\left(L_{q h}+L_{d h}\right) / 2, L_{\mathrm{dif}}=\left(L_{q h}-L_{d h}\right) / 2$, and $L_{\text {dif_c }}^{2}=L_{\text {dif }}^{2}+L_{d q h}^{2}$.

When $\left[i_{q h}^{e}+\left(L_{d q h} / L_{q h}\right) i_{d h}^{e}\right]$ in (3) is controlled to be zero, the error in the estimated rotor position will be zero. Therefore, the accuracy of the parameters $L_{d q h}$ and $L_{q h}$ directly affects the rotor position estimation accuracy. Due to magnetic saturation, $L_{d q h}$ and $L_{q h}$ both vary with $i_{d}$ and $i_{q}$. The variation can be obtained by either finite-element analysis or measurements.

\section{PREDicted AND MEASURED InCREMENTAL SELF} AND MUTUAL INDUCTANCES

$L_{d h}, L_{q h}, L_{d q h}$, and $L_{q d}$, are defined as

$$
\begin{cases}L_{d h}=\partial \psi_{d} / \partial i_{d}, & L_{d q h}=\partial \psi_{d} / \partial i_{q} \\ L_{q d h}=\partial \psi_{q} / \partial i_{d}, & L_{q h}=\partial \psi_{q} / \partial i_{q}\end{cases}
$$

where $\psi_{d}$ and $\psi_{q}$ are the $d$ - and $q$-axis flux linkages. The finiteelement predicted incremental self and mutual inductances are determined according to

$$
\left\{\begin{array}{l}
L_{d h}=\left[\psi_{d}\left(i_{d}+\Delta i_{d}, i_{q}, \Phi_{m}\right)-\psi_{d}\left(i_{d}, i_{q}, \Phi_{m}\right)\right] / \Delta i_{d} \\
L_{q h}=\left[\psi_{q}\left(i_{d}, i_{q}+\Delta i_{q}, \Phi_{m}\right)-\psi_{q}\left(i_{d}, i_{q}, \Phi_{m}\right)\right] / \Delta i_{q} \\
L_{d q h}=\left[\psi_{d}\left(i_{d}, i_{q}+\Delta i_{q}, \Phi_{m}\right)-\psi_{d}\left(i_{d}, i_{q}, \Phi_{m}\right)\right] / \Delta i_{q} \\
L_{q d h}=\left[\psi_{q}\left(i_{d}+\Delta i_{d}, i_{q}, \Phi_{m}\right)-\psi_{q}\left(i_{d}, i_{q}, \Phi_{m}\right)\right] / \Delta i_{d}
\end{array}\right.
$$

where $\Phi_{m}$ is the flux linkage due to permanent magnets.

Practically, the $d$ - and $q$-axis incremental self and mutual inductances are measured indirectly from the high-frequency currents, $i_{d h}^{I}, i_{q h}^{I}, i_{d h}^{I I}$, and $i_{q h}^{I I}$, which flow when the high-frequency voltage $v_{\text {sig }}$ is applied to the $d$ - and $q$-axes [5]. $i_{d h}^{I}$ and $i_{q h}^{I}$ are 


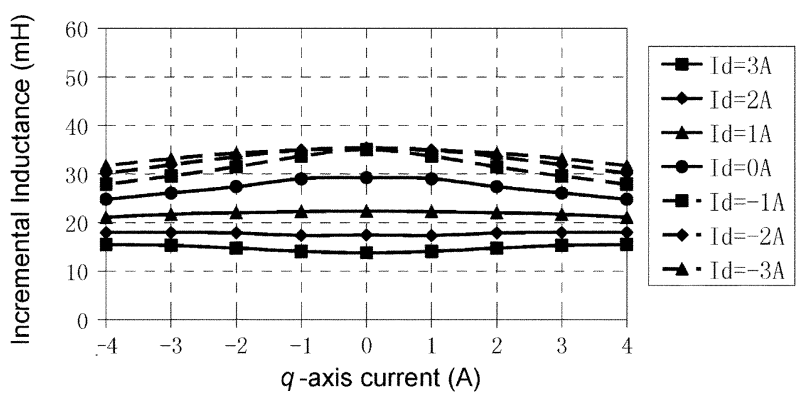

(a)

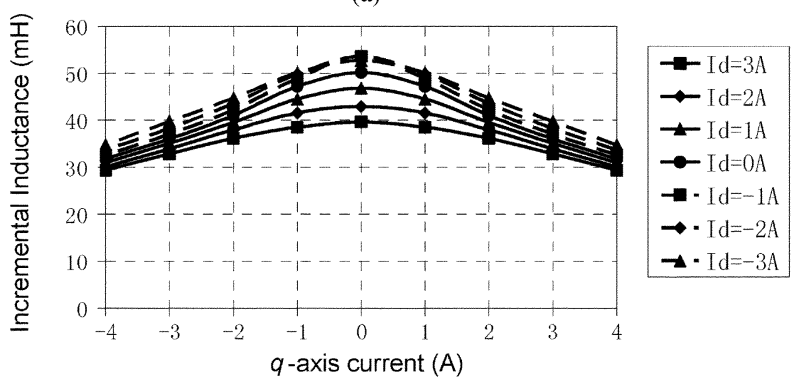

(b)

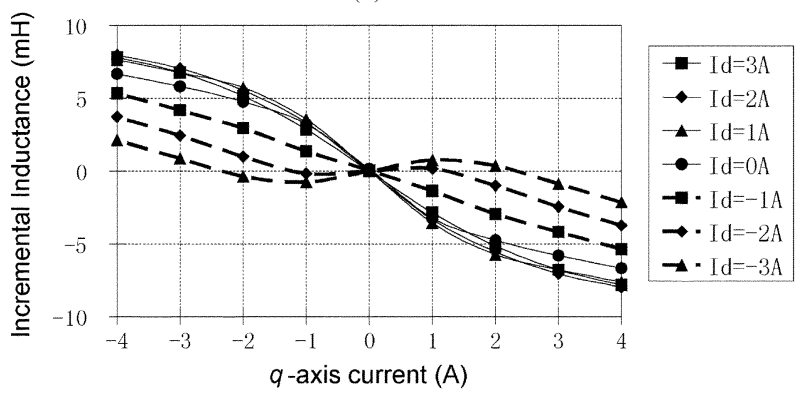

(c)

Fig. 1. Finite-element predicted incremental self and mutual inductances. (a) $d$-axis incremental inductance, $L_{d h}$ (b) $q$-axis incremental inductance, $L_{q h}$ (c) $d q$-axis incremental mutual inductances, $L_{d q h}$ and $L_{q d h}$.

the high-frequency components of the $d$ - and $q$-axis currents, which result when $v_{\text {sig }}$ is applied to the $d$-axis, i.e., $v_{d h}=v_{\text {sig }}$, when the BLAC motor is driven with its actual rotor position being measured via an encoder, while $i_{d h}^{I I}$ and $i_{q h}^{I I}$ are high-frequency components of the $d$ - and $q$-axis currents when $v_{\text {sig }}$ is applied to the $q$-axis, i.e., $v_{q h}=v_{\text {sig }}$, Therefore, from (2)

$$
\left[\begin{array}{cc}
v_{\text {sig }} & 0 \\
0 & v_{\text {sig }}
\end{array}\right]=\left[\begin{array}{cc}
L_{d h} & L_{d q h} \\
L_{q d h} & L_{q h}
\end{array}\right] \cdot p\left[\begin{array}{cc}
i_{d h}^{I} & i_{d h}^{I I} \\
i_{q h}^{I} & i_{q h}^{I I}
\end{array}\right]
$$

and, hence

$$
\left[\begin{array}{cc}
L_{d h} & L_{d q h} \\
L_{q d h} & L_{q h}
\end{array}\right]=\frac{1}{2 \pi f_{\mathrm{HF}}}\left[\begin{array}{cc}
v_{\mathrm{sig}} & 0 \\
0 & v_{\mathrm{sig}}
\end{array}\right]\left[\begin{array}{cc}
i_{d h}^{I} & i_{d h}^{I I} \\
i_{q h}^{I} & i_{q h}^{I I}
\end{array}\right]^{-1}
$$

where $f_{\mathrm{HF}}$ is the frequency of $v_{\mathrm{sig}}$.

The 2-D finite element predicted and measured varation of the incremental self and mutual inductances with both $i_{d}$ and $i_{q}$ are shown in Figs. 1 and 2, respectively, for a six-pole BLAC motor which has an interior PM rotor, its rated speed, torque, and current being $1000 \mathrm{rpm}, 4.0 \mathrm{Nm}$, and 4.0 A, respectively. As will be seen, the predictions compare well with measurements. However, the predicted values are somewhat smaller than the measured results due to the neglect of end effects, dimensional

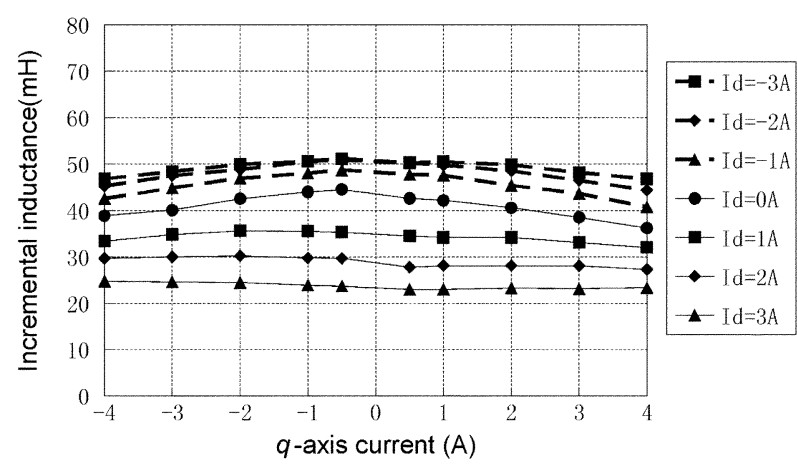

(a)

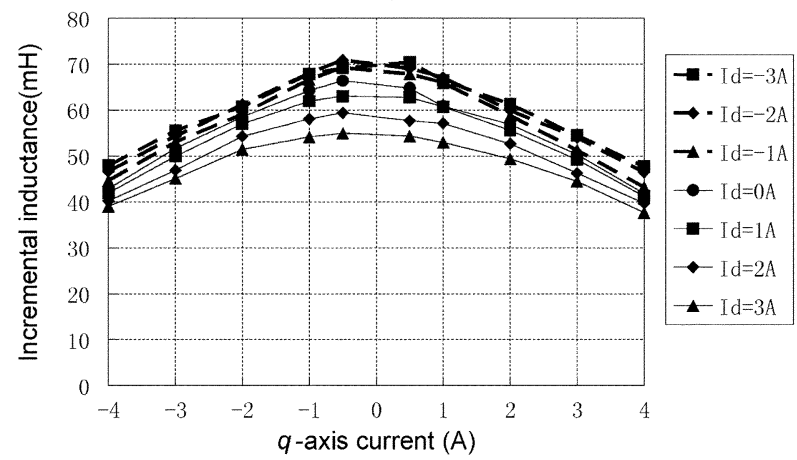

(b)

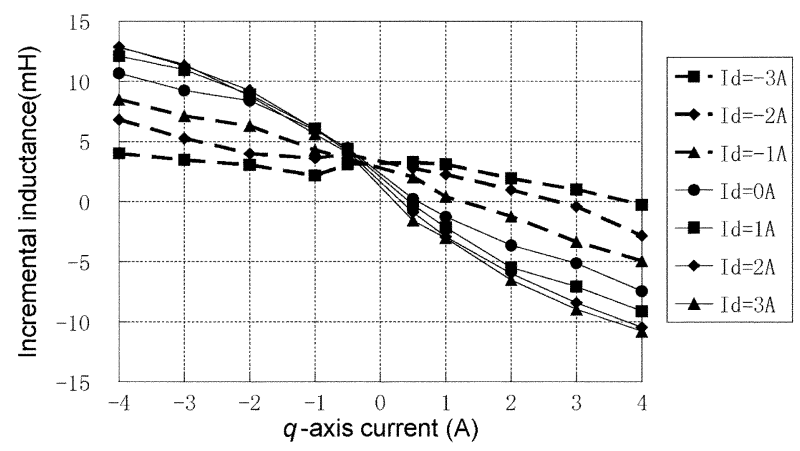

(c)

Fig. 2. Measured incremental self and mutual inductances. (a) $d$-axis incremental inductance, $L_{d h}$ (b) $q$-axis incremental inductance, $L_{q h}$ (c) $d q$-axis incremental mutual inductances, $L_{d q h}$ and $L_{q d h}$.

tolerances and uncertainties in the localized $B-H$ characteristics of the stator and rotor laminations, as well as the influence of eddy currents. However, as will be evident from (3), and also Section IV, it is the ratio $L_{d q h} / L_{q h}$ which determines the accuracy of the rotor position estimation.

\section{MEASUREMENT OF ERROR IN ESTIMATED Rotor POSITION}

From (3), both $L_{d q h}$ and $L_{q h}$ are required to determine the error in the estimated rotor position in a signal-injection-based sensorless control scheme. Fig. 3 compares finite-element predicted and measured ratios of $L_{d q h} / L_{q h}$, deduced from Figs. 1 and 2, respectively. As can be seen, although the predicted incremental inductances are smaller than the measured values, the predicted and measured ratios of $L_{d q h} / L_{q h}$ agree well. Hence, either can be used to improve the accuracy of the estimated rotor position. However, interpolation to account for the fact that the incremental inductances vary with both $i_{d}$ and $i_{q}$ is too complex to implement on a DSP. Therefore, much simpler approxi- 


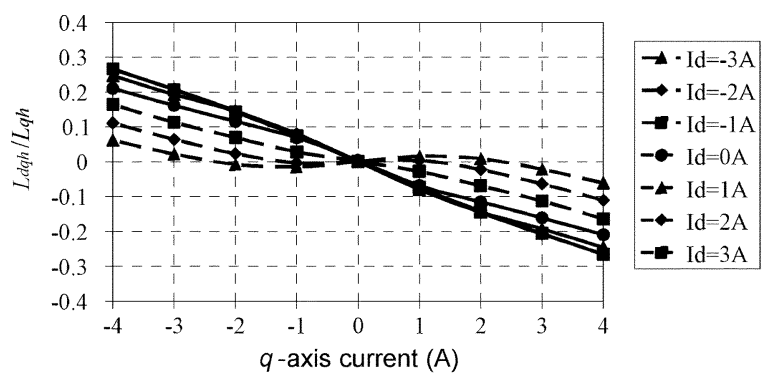

(a)

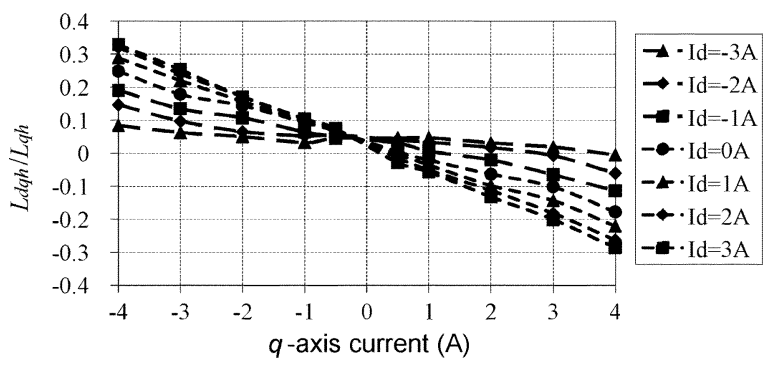

(b)

Fig. 3. Comparison of predicted and measured ratio of $L_{d q h} / L_{q h}$. (a) Predicted. (b) Measured.

mation functions are used to represent the variation in the ratio $L_{d q h} / L_{q h}$, viz.

$$
\frac{L_{d q h}}{L_{q h}}= \begin{cases}k_{1} \cdot i_{q}^{e}, & i_{d}^{e} \geqslant 0 \\ \left(k_{1}+k_{2} i_{d}^{e}\right) \cdot i_{q}^{e}, & i_{d}^{e}<0\end{cases}
$$

where $k_{1}$, and $k_{2}$ are constant coefficients. For the machine under consideration, $k_{1}=-0.050 \mathrm{~A}^{-1}, k_{2}=-0.009 \mathrm{~A}^{-2}$ from finite-element analysis predictions, while the values deduced from measurements are $k_{1}=-0.060 \mathrm{~A}^{-1}, k_{2}=$ $-0.011 \mathrm{~A}^{-2}$.

The proposed signal-injection-based sensorless control scheme remains essentially similar to that described in [4] in which $d q$-axis cross coupling was neglected. However, the error in the estimated rotor position, which is calculated by (3), is now considered. The scheme is implemented on a TMS320C31 DSP, and a precision encoder is used to measure the actual rotor position, and enable the error to be determined. The frequency of the AD sampling, the control loop, and the PWM are all $5 \mathrm{kHz}$, and the injected sinusoidal voltage is $35 \mathrm{~V}, 330 \mathrm{~Hz}$.

As shown in Fig. 4(a), when conventional signal-injection-based sensorless control is employed, i.e., $L_{d q h} / L_{q h}$ is neglected, the error in the estimated rotor position can be large, and depends on both $i_{d}$ and $i_{q}$, the average error in the motor under consideration being $15.4^{\circ}$. When $d q$-axis cross coupling is accounted for, the accuracy of the estimated rotor position is improved significantly, as shown in Fig. 4(b) and (c). For example, the average errors are reduced to $2.4^{\circ}$ and $1.5^{\circ}$, respectively, when the finite-element predicted and measured $L_{d q h} / L_{q h}$, Fig. 3(a) and (b), are employed, the error being slightly smaller when the measured $L_{d q h} / L_{q h}$ is used since it accounts for the end-winding inductances.

\section{CONCLUSION}

An improved implementation of high-frequency signal injection sensorless control of a BLAC motor, which accounts for cross-coupling magnetic saturation between the $d$ - and $q$-axes, has been demonstrated. The required parameters are obtained

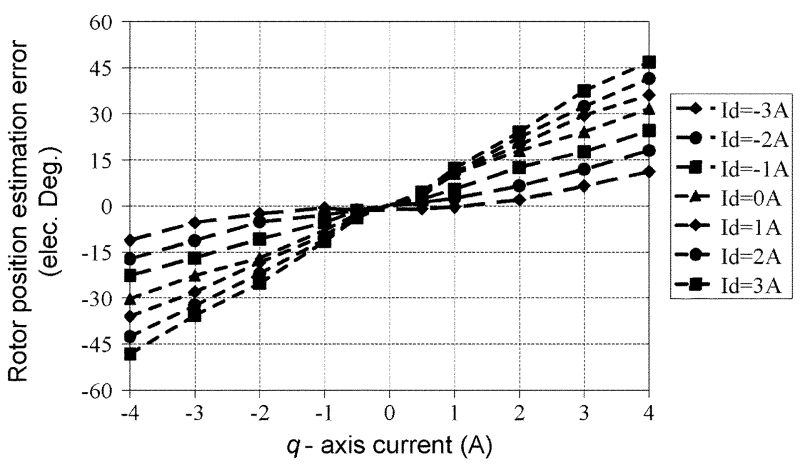

(a)

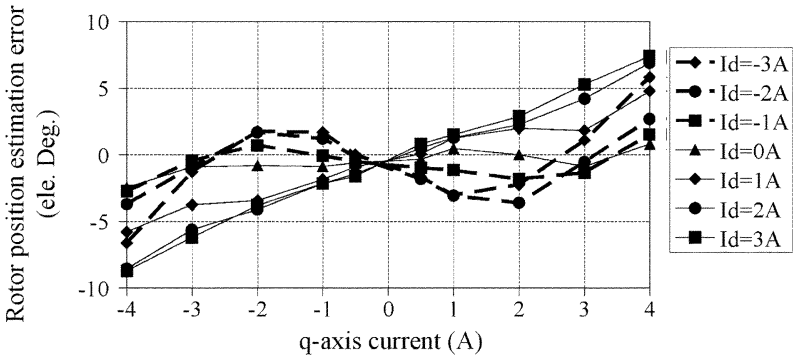

(b)

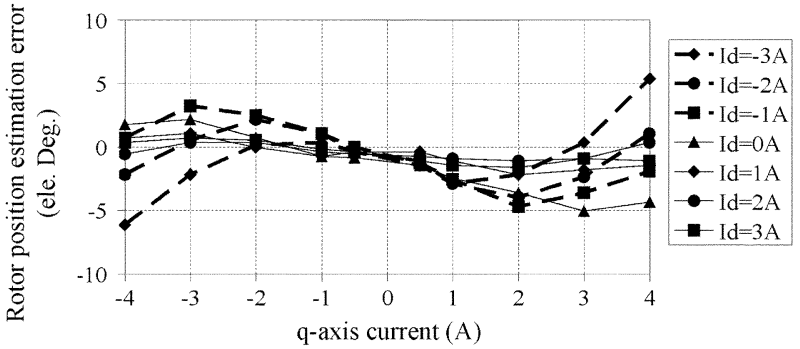

(c)

Fig. 4. Measured error in estimated rotor position. (a) Neglecting $L_{d q h} / L_{q h}, \operatorname{avg}\left(\left|\theta_{r}^{e}-\theta_{r}\right|\right)=15.4^{\circ}$. (b) Using finite-element calculated $L_{d q h} / L_{q h}, \operatorname{avg}\left(\left|\theta_{r}^{e}-\theta_{r}\right|\right)=2.4^{\circ}$. (c) Using measured $L_{d q h} / L_{q h}, \operatorname{avg}\left(\left|\theta_{r}^{e}-\theta_{r}\right|\right)=1.5^{\circ}$.

by either finite-element analysis or from measurements. It has been shown that the error in the estimated rotor position can be reduced significantly.

\section{REFERENCES}

[1] M. J. Corley and R. D. Lorenz, "Rotor position and velocity estimation for a salient-pole permanent magnet synchronous machine at standstill and high speed," IEEE Trans. Ind. Appl., vol. 34, no. 4, pp. 784-789, Jul.-Aug. 1998.

[2] P. Guglielmi, M. Pastorelli, and A. Vagati, "Cross saturation effects in IPM motors and related impact on zero-speed sensorless control," Conf. Rec. IEEE-IAS Annu. Meeting, vol. 4, pp. 2546-2552, 2005.

[3] B. Stumberger, G. Stumberger, D. Dolinar, A. Hamler, and M. Trlep, "Envaluation of saturation and cross-magnetization effects in interior permanent-magnet synchronous motor," IEEE Trans. Ind. Appl., vol. 39, no. 5, pp. 1264-1271, Sep.-Oct. 2003.

[4] J. H. Jang, S. K. Sul, J. I. Ha, K. Ide, and M. Sawamura, "Sensorless drive of surface-mounted permanent-magnet motor by high-frequency signal injection based on magnetic saliency," IEEE Trans. Ind. Appl., vol. 39, no. 4, pp. 1031-1039, Jul.-Aug. 2003.

[5] S. Ogasawara and H. Akagi, "Implementation and position control performance of a position-sensorless IPM motor drive system based on magnetic saliency," IEEE Trans. Ind. Appl., vol. 34, no. 4, pp. 806-812, Jul.-Aug. 1998. 